\title{
The Role of Dark Personalities and the Setting in Explaining Counterproductive Work Behavior among Nurses in China
}

\author{
Aaron Cohen ${ }^{1} \&$ Ying Liu $^{2}$ \\ ${ }^{1}$ School of Political Science, Division of Public Administration, University of Haifa, Israel \\ ${ }^{2}$ School of Public Administration, Renmin University of China \\ Correspondence: Aaron Cohen, School of Political Science, Division of Public Administration, University of \\ Haifa, Haifa, 3498838, Israel.
}

Received: May 13, 2021

Accepted: June 17, 2021

Online Published: June 25, 2021

doi:10.5539/ijps.v13n3p23

URL: https://doi.org/10.5539/ijps.v13n3p23

\begin{abstract}
The goal of this study was to examine the relationship between dark triad personality (DTP) and counterproductive work behavior (CWB). In addition, the study also examined the main effects and the moderated relationship of four situational variables: organizational justice, organizational transparency, psychological contract breach, and perceived accountability. Data were collected at two hospitals in Beijing, China, and included 259 randomly selected nurses. The main effect results showed that nurses with higher levels of Machiavellianism demonstrated higher levels of organizational and interpersonal CWB. Furthermore, higher levels of psychopathy were related to higher levels of interpersonal CWB, but not organizational CWB. There was no relationship between narcissism and CWB. The main effect findings did not reveal any significant relationship between the four situational variables and CWB. However, the interaction analyses revealed five significant interactions that point to transparency as an important moderator. The paper concludes with conceptual as well as practical implications for the nursing profession.
\end{abstract}

Keywords: dark triad, counterproductive work behavior, organizational justice, psychological contract breach, accountability, transparency, nurses in China

\section{Introduction}

Counterproductive work behavior (CWB) has attracted a great deal of interest among scholars from different fields (Carpenter, Whitman, \& Amrhein, 2020; Schilpzand et al., 2016; Cohen \& Diamant, 2017). Employees who engage in CWB know that they are breaking common ethical and moral codes with the aim of damaging the organization and/or its employees to achieve their personal goals. Such activities threaten the welfare of healthcare organizations and their employees. Activities that harm the organization and its members in the healthcare setting can cause mistakes, low patient and employee satisfaction, high turnover, and higher hospital costs (Yao, 2019). While many studies have been performed on CWB in a variety of settings (Berry et al., 2007; Berry et al., 2012; Schyns \& Schilling, 2013; Bowling \& Beehr), few studies have attempted to explore why nurses perform CWB (Zaghini et al., 2016). One of the explanations identified in recent years to better understand the reasons for performing CWB is the presence of dark personalities in work organizations (Cohen, 2018; Nuzulia \& Why, 2020; Thibault \& Kelloway, 2020; Searle \& Rice, 2020). There is therefore a growing interest in research on dark personalities in the workplace; however, more studies are needed to better understand this phenomenon (Palmer et al., 2017).

Dark triad personalities (DTP) encompass three subclinical personality traits that are similar in some core characteristics; however, each one has unique characteristics that make them conceptually different-narcissism, Machiavellianism, and psychopathy (Cohen, 2016). The unique characteristics of narcissism include a sense of entitlement and perceived superiority, while psychopathy includes callousness, lack of empathy and remorse, and impulsivity. Machiavellians emphasize in their behavior the use of manipulation and cunning intended to weaken others. All three DTP may perceive CWB as a way to channel aggression or achieve revenge. That is, CWB is a way for them to confirm their position in the organization and to gain power and resources (Palmer et al., 2017).

An important aspect that deserves attention is the fact that most research on the relationship between DTP and CWB has been performed in Western cultures. Therefore, few studies have considered the possible effect of 
different cultures on this relationship (Grijalva \& Newman, 2015). In addition, few studies have examined the relationship between DTP and CWB in the healthcare setting and, more specifically, in the nursing profession (Ghislieri et al., 2019). Finally, there is a call to advance and examine possible moderators in the relationship between DTP and CWB (Cohen, 2016). This study addresses the three issues raised above. To this end, it will first examine the relationship between DTP and CWB in a non-Western culture, such as the Chinese culture (Liu \& Cohen, 2018). Second, it will examine the above relationship in a setting that seems to have been overlooked in terms of this relationship, that is, the healthcare setting and, specifically, the nursing profession (Turmipseed \& Was, 2020). Third, it will advance and examine the role of the following four moderators in the above relationship: organizational justice, organizational transparency, psychological contract, and perceived accountability (Cohen, 2016).

\section{Literature Review and Hypotheses}

\subsection{Narcissism and CWB}

Narcissists may do everything that is required to boost their ego, even pushing others down and engaging in CWB to achieve this goal (Baloch et al., 2017). Based on a positive relationship between head nurses' narcissism and their subordinates' CWB, Ali and Johl (2020) concluded that head nurses' narcissism increased CWB among their subordinates. Because the needs of lower-level nurses are constantly ignored by their narcissistic supervisors, they experience frustration and eventually retaliate with CWB. This paper examines the relationship between narcissism and CWB in a traditional collectivist culture, namely, China (Liu \& Cohen, 2018). In collectivist cultures, great importance is placed on norms of mutuality, and individuals are less likely to accept violations of social exchange performed by the DTP. Self-promotion, manipulation of colleagues, and antisocial behavior are perceived as disloyalty to the group, and are sanctioned by the group (O'Boyle et al., 2012). Thus, collectivist cultures create conditions that limit the expression of CWB by narcissistic personalities. That is, the cues in a collectivist culture suggest to narcissists that individuals who violate the group norms, or harm individuals or the organization, will face harsher sanctions (Grijalva \& Newman, 2015). Based on the above, one can expect a modest relationship between narcissism and CWB because of the cultural setting of this study. In line with this, the following hypothesis is proposed:

\section{Hypothesis 1: Narcissism is positively and modestly related to CWB.}

\subsection{Psychopathy and CWB}

Psychopaths harm others to pursue self-interest. For example, they can distract employees' attention from a particular task so that they can work on their own agenda. Their ruthless personality and ambition to achieve their goals, even if they need to harm others to achieve them, may cause them to engage in CWB (Baloch et al., 2017). Western societies are more tolerant toward psychopathic behavior. This is because they are more materialistic and competitive than traditional collectivist societies, thus endorsing psychopathic traits. Western societies expedite the masking of psychopathic behavior because it aligns better with accepted Western societal norms, where self-fulfillment, personal advancement, and surmounting difficulties in achieving their career goals are perceived as respectable and advantageous (Boddy, 2011).

However, Boddy (2010) mentioned Stout (2005a, 2005b), who contends that traditional collectivist cultures that endorse the advancement of the group, rather than the individuals within the group, and teach the importance of the collective, may create a more unsupportive environment for the psychopath than in a more Western individualistic culture. Therefore, in a traditional collectivist culture, such as China, behaviors that constitute psychopathic traits may be undesirable because individuals in a collectivist culture have a strong sense of obligation to their family and society (Robertson et al., 2016). Accordingly, one can expect a modest relationship between psychopathy and CWB because of the cultural setting of this study. In line with this, the following hypothesis is proposed:

\section{Hypothesis 2: Psychopathy is positively and modestly related to CWB.}

\subsection{Machiavellianism and CWB}

Machiavellians are impetuous and unreliable in their interpersonal interactions and are not concerned about the outcomes of their behaviors. Such emotions increase the possibility that Machiavellians will be involved in CWB (Baloch et al., 2017). That is, Machiavellians are involved in manipulative CWB when facing difficulties in achieving their goals (Lee et al., 2020b). In the cultural setting of China, the "thick and dark theory" (i.e., to behave in a dishonest, shameless, and hard-hearted manner) is well known to the people and is called "oriental Machiavellianism" (Geng et al., 2016). According to Geng et al. (2016) In 1911, Li Zhong Wu advanced the "thick and dark theory," but it is still relevant for Chinese society today. The theory emphasizes the importance 
of avoiding responsibility and accountability for one's actions and for making one's activities appear more valuable and inspiring than they really are. According to Zhao et al. (2016), Machiavellianism relates to antisocial behaviors only when there is no chance of exposure.

As Machiavellianism seems to be rooted in Chinese culture, one can expect a strong and positive relationship between Machiavellianism and CWB.

Hypothesis 3: Machiavellianism is positively related to CWB.

\subsection{Contextual Variables}

As noted by Cohen (2016), DTP, like predators, is very sensitive to cues from the environment. Based on these cues, they determine whether to attack and the best timing to strike. Therefore, it is important to examine how DTP perceptions of possible organizational constraints affect the relationship between DTP and CWB (O'Boyle et al., 2012; Palme et al., 2017). Situational cues that may affect DTP decisions on whether and when to act should be of interest (Youli \& Chau, 2015). The importance of situational constraints and their interactions with personality has been acknowledged and should be examined in the context of the relationship between DTP and CWB. Thus, four moderators were investigated in this study.

\subsubsection{Organizational Justice}

According to equity theory (Adams, 1965), employees compare their ratio of outcomes (e.g., promotion, raises, pay) to inputs (e.g., education, effort, training) with the ratio of a referent other (e.g., colleagues and employees in other industries or organizations). When the ratio of the outcome is equal to the ratio of the input, equity is perceived by the employee. When there is a discrepancy between outcomes and inputs, employees believe that they are not compensated equally and fairly, and they act to reestablish equity. One option for employees who feel that they are not treated fairly and equally is to retaliate by engaging in CWB (Cohen-Charash \& Mueller, 2007).

The DTP is no exception, and those high in DTP may retaliate more strongly. That is, psychopaths, narcissists, and Machiavellians have different needs and may respond aggressively in different situations (Baka, 2018); perceptions of injustice may be one such situation. Geraghty (2019) found that employees high in DTP who perceived high organizational justice engaged in less CWB, while those who perceived high organizational injustice engaged in more CWB. Grijalva and Harms (2014) found that narcissists are more likely to perceive organizational injustice because their personality leads them to perceive their performance more positively than it actually is. This causes them to perceive a greater imbalance between their outcomes and inputs, and probably to retaliate with more CWB.

Hypothesis 4a: Organizational justice is negatively related to $C W B$.

Hypothesis 4b: The relationship between DTP and CWB will be stronger for those who perceive low organizational justice than for those who perceive high organizational justice.

\subsubsection{Transparency}

According to Cicala et al. (2014), based on agency theory, transparency emphasizes the ability of a principal to monitor and control an agent's activities. Transparency is defined as the ability to obtain information that permits external agents to monitor the work or performance of the organization and/or the actor (Grimmelikhuijsen \& Welch, 2012). Transparency throughout the organizational structure is an important condition to reduce the potential for prohibited transactions. Practices such as record-keeping and reporting can be applied by the organization to document the major attributes of its compliance effort and to control and monitor its programs for effectiveness. Even reporting and controlling negligible incidents in the organization is important because it transmits a clear policy from the organization that there will be zero tolerance for any problematic behavior. Otherwise, members of the organization may believe that minor misconduct is tolerated (Luo, 2005). Based on this, one can expect that high transparency will be negatively related to CWB.

This contention can lead to further arguments. One can expect that, in situations of low job control (e.g., low transparency), a DTP is the most likely employee to engage in CWB. This is because low transparency generates an organizational setting, which makes it difficult for DTPs to engage in CWB (Baka, 2018). In contrast, uncertainty and ambiguity provide a perfect setting for predators who are willing to retaliate toward the organization or some of its members (Johns, 1999). Like predators, they feel that an environment with low transparency is safer for them, and there is little chance for them to be caught. To demonstrate, Yang and Diefendorff (2009) found a positive relationship between perceived ambiguity and CWB.

Hypothesis 5a: Transparency will be negatively related to CWB. 
Hypothesis 5b: The relationship between DTP and CWB will be stronger among those who perceive low transparency than those who perceive high transparency.

\subsubsection{Psychological Contract Breach}

A psychological contract signifies the mutual beliefs and the agreement between employers and employees regarding the informal obligations between them (Cohen, 2015; Li \& Chen, 2018). These mutual expectations are assumed and subjective; they are neither formal nor written (Pan et al., 2018). If one side perceives that the promises made by the other side are not fulfilled, then there will be the perception of a breach of the psychological contract. This will be demonstrated by a feeling of violation and frustration, which will increase the tendency to retaliate by engaging in CWB (Griep et al., 2018; Li \& Chen, 2018; Chau et al., 2011). The experience of being treated unfairly and the feeling of betrayal are major stimuli of the desire to enact revenge by engaging in CWB (Furnham \& Siegel, 2012). Studies have found empirical support for the relationship between psychological contract breaches and CWB (Griep et al., 2018; Jensen et al., 2010).

Despite the possibility that DTP will be more prone to retaliate in response to negative treatment, few studies have investigated the influence of DTP on psychological contract breach dynamics (Zagenczyk et al., 2017). DTP perceive their relationship with the organization as transactional in nature because they are emotionally distant, do not trust others, and do not believe in fair exchange (Pan et al., 2018; O'Boyle et al., 2012). Thus, DTP does not hesitate to engage in CWB to achieve their goals, and a psychological contract breach may provide them with a good reason to do so.

To illustrate, Machiavellians are less disposed to give the organization the "benefit of the doubt" when they perceive that a contract breach has occurred. Their basic nature is to perceive such events as a conspiracy or plot rather than as a mistake or coincidence. Machiavellians may respond very aggressively in such situations by engaging more in CWB (Zagenczyk et al., 2017). Anger is one possible way to respond to unfair treatment; however, fake anger, demonstrated by a response to a psychological contract breach, can be used by subclinical psychopaths as an opportunity to gain egocentric goals by engaging in CWB (Boulter \& Boddy, 2020). Narcissism is also related to anger (Zagenczyk et al., 2017); thus, a psychological contract breach will activate the negative predispositions of narcissists as they tend to respond more strongly and quickly toward those who threaten to harm or derogate them. Therefore, narcissistic employees will not hesitate to engage in CWB to harm the organization and/or members within it whom they perceive as responsible for the contract breach (Zagenczyk et al., 2017).

\section{Hypothesis 6a: There is a positive relationship between psychological contract breaches and CWB.}

Hypothesis 6b: The relationship between DTP and CWB is stronger among those who perceive a high psychological contract breach than among those who perceive a low psychological contract breach.

\subsubsection{Accountability}

Accountability is an important factor in the effective performance of organizational activities (Hochwarter et al., 2005; Mahmood et al., 2021) because organizations need to apply some control over their employees' behaviors (Ammeter et al., 2004). Employees look for clues about the acceptable standards of performance that are expected by those to whom they must be accountable. Without accountability, it will be almost impossible to maintain social and formal systems within an organization (Mahmood et al., 2021). Felt accountability can be defined as inferred or precise expectations that one's activities, performance, or decisions are important and will be noted by others. This is based on the awareness that a potential exists for the employee to receive rewards or sanctions (Hochwarter et al., 2005). It is reasonable to expect that DTP will perceive an organization with low accountability as a friendlier environment for their activities because they will not have to report to anyone about their activities; thus, they have a lower chance of being caught.

DTPs, by nature, are more sensitive to environmental clues in their environment (Martin et al., 2010). DTPs behave according to environmental clues and the perception that they are subject to a high degree of accountability discourages them from engaging in CWB because they believe that this increases the possibility of being caught. Therefore, it is expected that when DTPs believe they are accountable for a specific task or performance, they will hesitate to engage in CWB (Mahmood et al., 2021).

Hypothesis 7a: There is a negative relationship between perceived accountability and CWB.

Hypothesis 7b: The relationship between DTP and CWB will be stronger among those who perceive low accountability than those who perceive high accountability. 


\section{Methods}

\subsection{Subjects and Procedures}

The study was performed in two hospitals in Beijing. Participation was anonymous, and no incentives were provided to the nurses. The questionnaires were written in Chinese, and the translation was checked using a translation and back-translation process. The questionnaires were distributed to 205 randomly selected nurses in the first hospital and 75 nurses in the second hospital. In total, 259 nurses (92\% response rate) returned usable questionnaires: 190 from the first hospital (93\% response rate) and 68 from the second hospital (91\% response rate).

Overall, $93 \%$ of the participants were female, $63 \%$ were married, and $95 \%$ held non-managerial positions. The mean age of the participants was 31.5 years $(\mathrm{SD}=7.9)$. The mean tenure in the hospital was 10 years $(\mathrm{SD}=8.3)$, and the mean tenure in the healthcare profession was $10.6(\mathrm{SD}=8.4)$. Furthermore, $31 \%$ of the participants had one child under 18 years of age, and $69 \%$ had two children under 18 .

\subsection{Measures}

\subsubsection{Counterproductive Work Behavior (CWB)}

This two-dimensional construct was measured using the Bennett and Robinson (2000) scale. The first dimension covers organizational deviance (12 items; reliability 0.60 ), and the second dimension addresses interpersonal deviance (seven items; reliability $=0.86$ ). Confirmatory factor analysis showed a better fit of the two-dimensional model than the one-dimensional model.

Table 1. CFA for research constructs

\begin{tabular}{lccccccc}
\hline Model & $\mathbf{d f}$ & $\boldsymbol{\chi} \mathbf{2}$ & $\boldsymbol{\chi} \mathbf{2} / \mathbf{d f}$ & $\mathbf{C F I}$ & NFI & IFI & RMSEA \\
\hline$C W B s$ & & & & & & & \\
One-factor solution & 9 & 126.41 & $14.05^{* * *}$ & .84 & .83 & .84 & .22 \\
Two-factor solution & 8 & 80.20 & $10.02^{* * *}$ & .90 & .89 & .90 & .19 \\
Dark triad traits & & & & & & & \\
One-factor solution & 27 & 253.09 & $9.37^{* * *}$ & .78 & .76 & .78 & .18 \\
Three-factor solution & 24 & 70.39 & $2.93^{* * *}$ & .96 & .93 & .96 & .09 \\
\hline
\end{tabular}

Note. $N=259 . *=P \leq .05 ; * *=P \leq .01 ; * * *=P \leq .001$

\subsubsection{Dark Triad Personality (DTP)}

The 12-item scale of Jonason and Webster (2010) was used to measure personality types. Psychopathy (reliability $=0.60)$, narcissism (reliability $=0.87$ ), and Machiavellianism (reliability $=0.80$ ) were measured using four items. The results of the confirmatory factor analysis showed a better fit of the three-dimensional mode than the one-dimensional mode (see Table 1).

\subsubsection{Organizational Justice}

Niehoff and Moorman (1991) developed a three-dimensional scale to represent organizational justice, comprising the following dimensions: distributive justice (five items), procedural justice with formal procedures (six items), and interactional justice (nine items). The very high correlation among the three dimensions (above 0.80 ) required us to combine them into one, resulting in one scale with 20 items (reliability 0.95 ).

\subsubsection{Transparency}

The five-item scale developed by Ellis et al. (1999) was used in this study (reliability $=0.61$ ).

\subsubsection{Psychological Contract Breach}

The five-item scale of Robinson and Morrison (2000) was used for this variable (reliability $=0.81$ ).

\subsubsection{Felt Accountability}

This variable was measured using the eight-item scale developed by Hochwarter et al. (2005) and has good reliability (reliability $=0.86$ ). 


\subsubsection{Control Variables}

The study controlled for the two hospitals that participated in the study (hospital $1=0$; hospital $2=1$ ). Marital status was measured as a dichotomous variable $(0=$ not married; $1=$ married $)$, education was measured as an ordinal variable $(1=$ elementary school; $6=\mathrm{MA}$ or $\mathrm{PhD})$, and age was measured as a ratio variable. It should be noted that the above were control variables in previous studies that examined CWB (Berry et al., 2007).

\subsection{Data Analysis}

First, to test for common method variance, confirmatory factor analysis was applied using the SAS program following the method used by Brooke et al. (1988) and Mathieu and Farr (1991). Second, this study used Harman's one-factor test (Harman, 1967; Podsakoff \& Organ, 1986). The logic of this test is that if an exploratory factor analysis with all the study variables generates an eigenvalue above 0.50 for the first factor, then it is probable to conclude that there is a problem of common method variance. Third, a linear regression analysis was performed for all three tests. Finally, a moderation analysis using the PROCESS macro for SAS (Hayes, 2013) was performed with 24 interactions.

\section{Results}

Two Harman's factor tests were performed. In the first one, only seven attitudinal variables were entered into a principal component factor analysis (varimax rotation). The results of this analysis revealed that the first factor explained $28.4 \%$ of the variance. In the second Harman's test, two dependent variables were added to the seven attitudinal independent variables. The findings showed that the first factor explained $21.5 \%$ of the variance. Therefore, the first factor explained less than $50 \%$ of the variance. Thus, it can be concluded that the Harman tests preclude the possibility of common method variance.

Table 2. Descriptive statistics, reliabilities (in parentheses), and inter-correlations among research variables

\begin{tabular}{|c|c|c|c|c|c|c|c|c|c|c|c|c|c|c|c|}
\hline Variable & Mean & $\mathrm{SD}$ & 1 & 2 & 3 & 4 & 5 & 6 & 7 & 8 & 9 & 10 & 11 & 12 & 13 \\
\hline 1. Organization & .26 & .44 & & & & & & & & & & & & & \\
\hline 2. Age & 31.5 & 7.88 & $-.20 * *$ & & & & & & & & & & & & \\
\hline 3. Marital status & .61 & .49 & .01 & $.63 * * *$ & & & & & & & & & & & \\
\hline 4. Education & 3.48 & .61 & $-.46^{* * *}$ & $.16^{*}$ & $.20^{* * *}$ & & & & & & & & & & \\
\hline 5. Machiavellianism & 1.35 & .64 & -.00 & -.06 & -.09 & .11 & $(.80)$ & & & & & & & & \\
\hline 6. Psychopathy & 1.87 & .85 & -.03 & .05 & -.03 & .08 & $.36^{* * *}$ & $(.60)$ & & & & & & & \\
\hline 7. Narcissism & 2.05 & 1.21 & .06 & .00 & -.02 & .01 & $.47 * * *$ & $.60 * * *$ & $(.87)$ & & & & & & \\
\hline $\begin{array}{l}8 . \quad \text { Organizational } \\
\text { justice }\end{array}$ & 4.58 & 1.07 & .08 & $.15^{*}$ & $-.25^{* * *}$ & -.10 & .00 & $-.13 *$ & .08 & $(.95)$ & & & & & \\
\hline 9. Transparency & 4.42 & .87 & .06 & -.09 & $-.18 * *$ & -.07 & -.01 & -.05 & .08 &, $61 * * *$ & $(.61)$ & & & & \\
\hline $\begin{array}{l}\text { 10. Psychological } \\
\text { contract breach }\end{array}$ & 3.25 & 1.07 & -.04 & .08 & .10 & $.16^{*}$ & -.02 & .07 & -.08 & $-.59 * * *$ & $-.30^{* * *}$ & $(.81)$ & & & \\
\hline 11. Accountability & 4.52 & .74 & .11 & -.10 & -.11 & -.02 & .09 & -.10 & .11 & $.55^{* * *}$ & .51 & $-.17 * *$ & (.68) & & \\
\hline 12. CWBI & 1.18 & .51 & -.10 & .00 & $-.18^{* *}$ & .04 & $.39^{* * *}$ & $.27 * * *$ & $.20 * * *$ & .08 & .08 & -.05 & .07 & (.86) & \\
\hline 13. CWBO & 1.05 & .16 & -.01 & -.02 & $-.14 *$ & .07 & $.59^{* * *}$ & $.28 * * *$ & $.30 * * *$ & -.02 & -.09 & -.03 & .04 & $.54 * * *$ & (.60) \\
\hline
\end{tabular}

Note. $\mathrm{N}=259 . *=\mathrm{P} \leq .05 ; * *=\mathrm{P} \leq .01 ; * * *=\mathrm{P} \leq .001$

Organization: 0,1 ; Gender: $1=$ male; $2=$ female.

CWBI = Counterproductive work behavior individual; $\mathrm{CWBO}=$ Counterproductive work behavior organization .

Table 2 presents the descriptive statistics and intercorrelations among the research variables. The findings demonstrated acceptable reliability among the study variables, with none of the intercorrelations above 0.70 . This finding decreases the likelihood of multicollinearity. 
Table 3. Regression analyses (standardized coefficients) of demographic variables, dark triad, and situational variables on CWB dimensions

\begin{tabular}{|c|c|c|c|c|c|c|}
\hline \multirow[t]{2}{*}{ CWB } & \multicolumn{2}{|c|}{ Interpersonal CWBs } & \multicolumn{4}{|c|}{ Organizational CWBs } \\
\hline & Step 1 & Step 2 & Step 3 & Step 1 & Step 2 & Step 3 \\
\hline \multicolumn{7}{|l|}{ Independent variables } \\
\hline \multicolumn{7}{|l|}{ Demographic and control variables } \\
\hline 1. Organization $(0,1)$ & -04 & -.07 & -.08 & .08 & .04 & .05 \\
\hline 2. Age & $.17^{*}$ & $.16^{*}$ & $.15^{*}$ & .13 & .12 & .13 \\
\hline 3 Marital status &.$-.30 * * *$ & $-.24 * *$ & $-.22 * *$ & $-.25 * *$ & $-.18 * *$ & $-.20 * *$ \\
\hline 4. Education & .05 & -.02 & -.02 & .14 & .04 & .05 \\
\hline \multicolumn{7}{|l|}{ Independent variables } \\
\hline \multicolumn{7}{|l|}{ Dark triad traits } \\
\hline 5. Machiavellianism & & $.35 * * *$ & $.35 * * *$ & & $.56 * * *$ & $.55^{* * *}$ \\
\hline 6. Psychopathy & & $.17^{*}$ & $.19^{*}$ & & .06 & .06 \\
\hline 7. Narcissism & & -.06 & -.09 & & -.01 & .00 \\
\hline \multicolumn{7}{|l|}{ Situational variables } \\
\hline 8. Organizational Justice & & & .04 & & & -.04 \\
\hline 9. Transparency & & & .05 & & & -.12 \\
\hline 10. Psychological contract breach & & & -.02 & & & -.07 \\
\hline 11. Accountability & & & .02 & & & .05 \\
\hline $\mathrm{R}^{2}$ (adjusted) & $.06(.05)$ & $.22(.20)$ & $.23(.19)$ & $.04(.03)$ & $.38(.36)$ & $.39(.36)$ \\
\hline $\mathrm{F}$ for $\mathrm{R}^{2}$ & $4.06^{* *}$ & $9.67 * * *$ & $6.34 * * *$ & $2.70^{*}$ & $20.72 * * *$ & $13.72 * * *$ \\
\hline$\Delta \mathrm{R}^{2}$ & & .16 & .01 & & .33 & .01 \\
\hline $\mathrm{F}$ for $\Delta \mathrm{R}^{2}$ & & $16.14 * * *$ & 0.62 & & $42.88 * * *$ & 1.30 \\
\hline
\end{tabular}

The regression analysis results are presented in Table 3. Hypothesis 1 expected a modest and positive relationship between narcissism and CWB. The findings showed no significant relationship between narcissism and the two dimensions of CWB. This finding provided some support for the logic of Hypothesis 1. A positive and modest relationship between psychopathy and CWB was expected in Hypothesis 2. The findings revealed partial support for this hypothesis, as psychopathy was significantly and positively related to interpersonal CWB. However, it was not significantly related to organizational CWB (see Table 3). Hypothesis 3 was strongly supported by the data. As expected, the findings in Table 3 show a strong and positive relationship between psychopathy and the two dimensions of CWB.

Hypotheses $4 \mathrm{a}, 5 \mathrm{a}, 6 \mathrm{a}$, and $7 \mathrm{a}$, which expected significant direct relationships between the four situational variables and CWB, were rejected. None of the four situational variables were related to any of the CWBs (see Table 3). Hypotheses $4 \mathrm{~b}, 5 \mathrm{~b}, 6 \mathrm{~b}$, and $7 \mathrm{~b}$ expected that each of the situational variables would moderate the relationship between DTP and the two outcomes. Partial support was found for these hypotheses. Of the expected 24 interactions, only five significant interactions were found: two for interpersonal CWB, and three for organizational CWB. The significant interactions are presented below. 
Plot 1

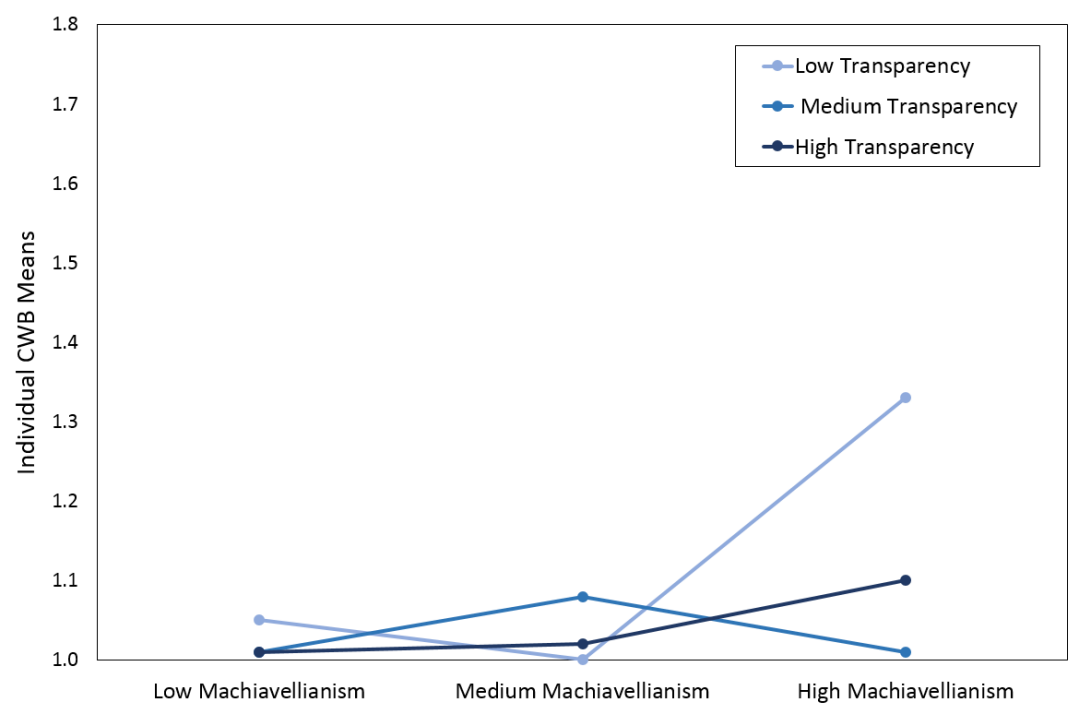

Plot 2

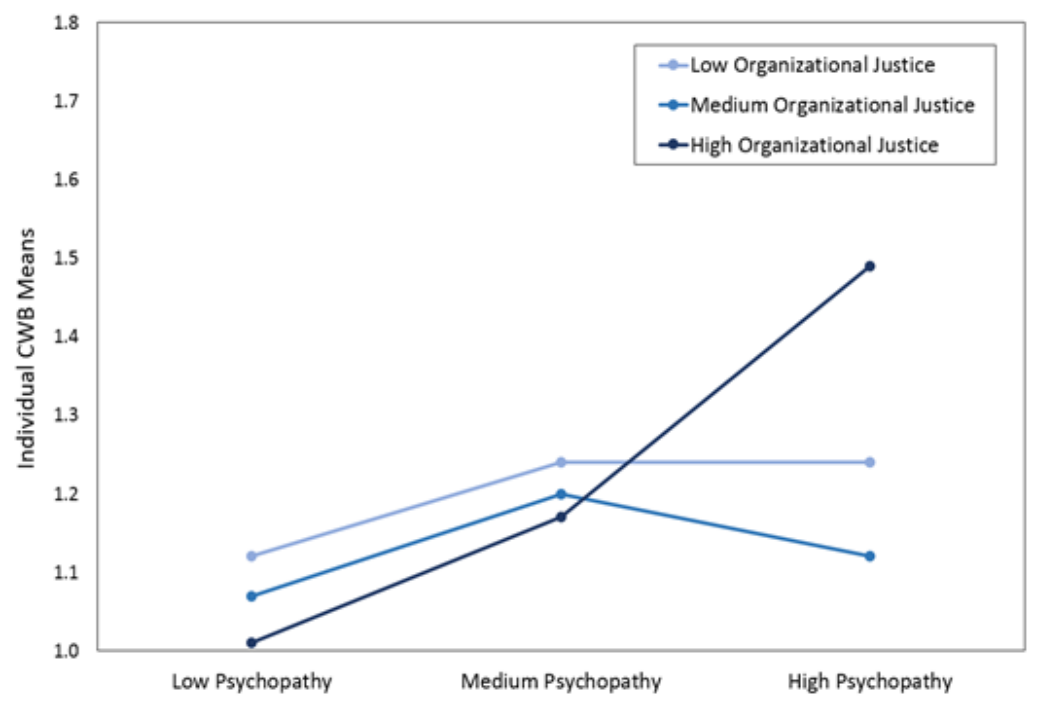

Figure 1. Plots of the significant interactions for interpersonal CWBs 
Plot 1

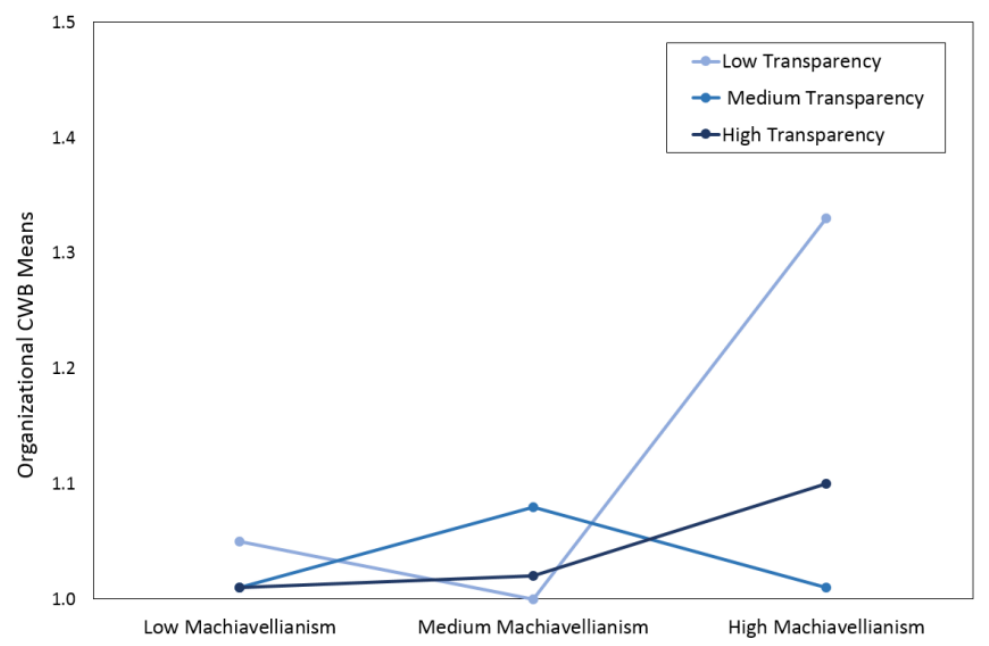

Plot 2

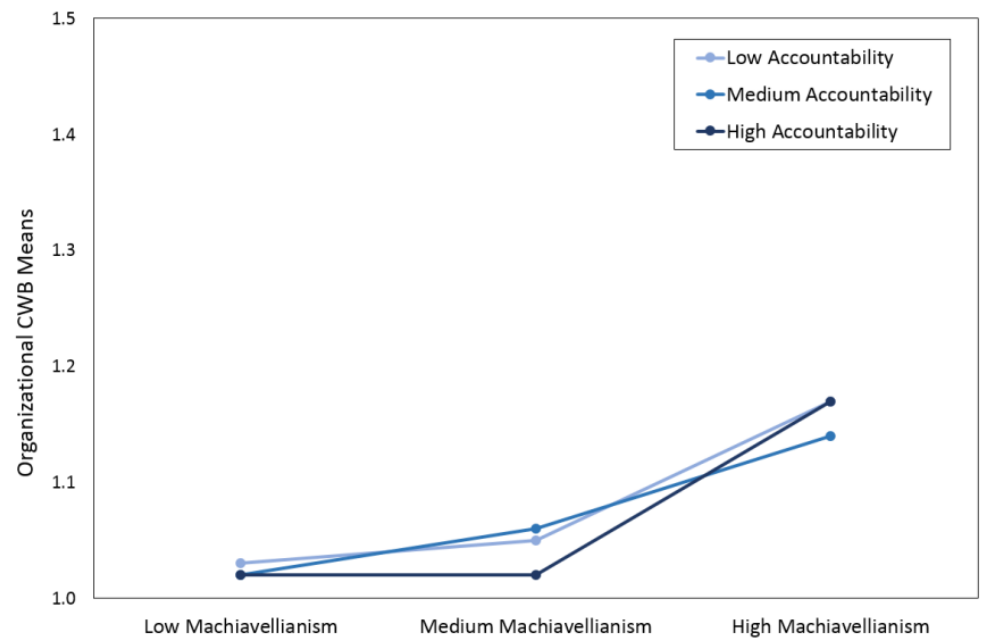

Plot 3

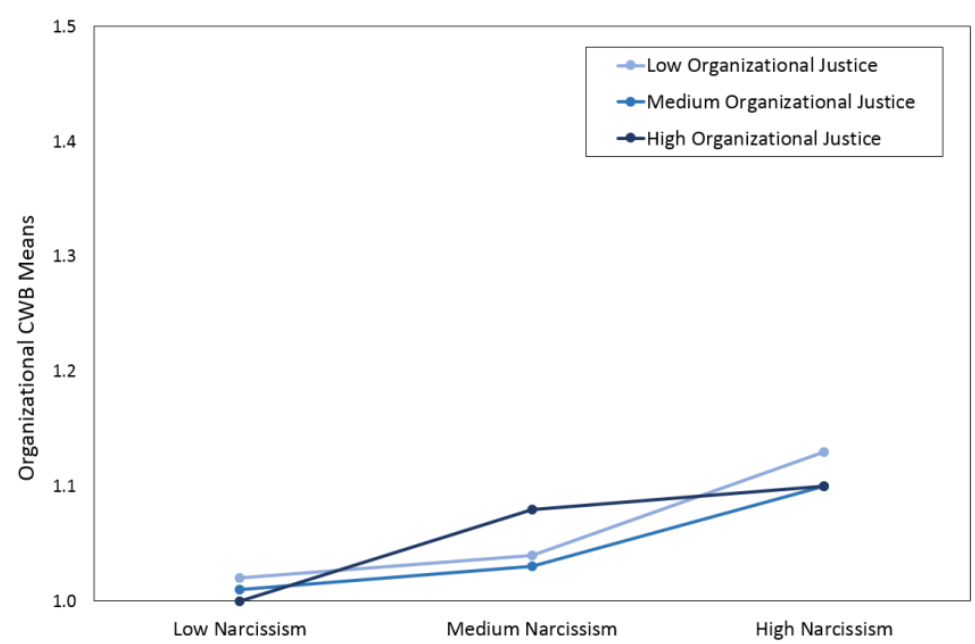

Figure 2. Plots of the significant interactions for organizational CWBs 
Two significant interactions were found in organizational justice. The first significant one showed that for those high in psychopathy, high organizational justice had a strong positive relationship with interpersonal CWB (Figure 1, Plot 2). It should be noted that Hypothesis $4 \mathrm{~b}$ expected the opposite. The second significant interaction showed that for those high in narcissism, a strong positive relationship between low organizational justice and organizational CWB was found, as expected in Hypothesis 4b (Figure 2, Plot 5); thus, this provides partial support for Hypothesis 4b. Two significant interactions were observed for the transparency. For high Machiavellianism, low transparency was strongly related to high levels of both interpersonal and organizational CWB, in accordance with Hypothesis 5b (Figure 1, Plot 1 and Figure 2, Plot 1). One significant interaction was found for accountability, as shown in Figure 2, Plot 2. The plot shows that for those high in Machiavellianism, both high and low accountability are related to organizational CWB. This does not support Hypothesis 6 b. Finally, a psychological contract breach was the only situational variable that did not interact with any of the DTP; thus, it did not support Hypothesis $7 \mathrm{~b}$.

While no specific hypotheses were advanced regarding the control variables, a strong effect of marital status should be noted. That is, unmarried nurses performed more individual and organizational CWB than married nurses. Additionally, there was a positive and significant relationship between age and individual CWB.

\section{Discussion}

\subsection{Conceptual Implications}

This study had two goals: first, to examine the relationship between DTP and CWB in a novel setting-China; and second, to examine this relationship among hospital nurses, a setting that has rarely been examined in this cultural context. Nurses' CWB leads to negative outcomes as to the quality of healthcare, the clinical process, and treatment of the patients (Zaghini et al., 2016). The main findings of this study were demonstrated in the strong relationship between Machiavellianism and the two dimensions of CWB. Modest relationships were found between psychopathy and $\mathrm{CWB}$, and no relationship was found between narcissism and the two dimensions of CWB.

A noteworthy finding of this study was the very strong and positive relationship between Machiavellianism and the two forms of CWB. Similar findings have been reported by Liu and Cohen (2018) among physicians in China. Furthermore, studies have revealed that East Asian countries such as China have a high Machiavellian culture (Zheng et al., 2017; Zaghini et al., 2016). Machiavellianism in China is characterized by low trust and a low control orientation. Other characteristics include status orientation and moral manipulation. A culture of trust is very important in the development of CWB in a Machiavellian culture because Machiavellians have no trust in interpersonal relationships. When the organization has no culture of trust, there is a higher likelihood of psychological contract breaches and reduced perceptions of fairness among employees. Consequently, employees will have no trust in their leaders, colleagues, and organization. This mindset of distrust can cause employees to engage in CWB (Zheng et al., 2016). This may explain the strong relationship found between high levels of Machiavellianism and CWB in the context of this study.

Psychopaths and their behavior may be perceived differently in different cultures, particularly in collectivist versus individualistic cultures (Smith \& Lilienfeld, 2013). Those high in psychopathy have affective shortages, low empathy, and callousness (Schilbach et al., 2020). This description explains the relationship between psychopathy and organizational CWB. To illustrate, harming individuals may be perceived as somewhat permissive in comparison to causing damage to the collective, that is, the organization. However, because CWB plays a significant role in organizational success and survival, they will hesitate to cause damage to the organization, which is a collectivist entity and represents the collectivist values of the Chinese culture.

According to Li et al. (2020), high psychopathy evident in the Chinese setting makes these individuals more likely to make utilitarian judgments than deontological judgments. However, Chinese culture blends individual interests with collective ones, and stresses an atmosphere of self-sacrifice and dedication. Confucianism accentuates daily ethics and leads to a collectivist inclination, and an orientation toward the interests of others; it emphasizes the interests of the majority over the interests of the minority. Such a setting creates a culture that encourages psychopaths to harm vulnerable individuals in the organization, which is perceived in collectivist terms; thus, the organization is perceived as being unable to act against vulnerable individuals in the workplace (Li et al., 2020). This may explain the significant relationship between psychopathy and individual CWB, as well as the insignificant relationship with organizational CWB that represents collective interests.

The insignificant relationship between narcissism and CWB is expected in Chinese collectivist cultures. Individuals in a collectivist culture are expected to be humbler about their personal achievements and status. Furthermore, they are expected to perceive the situation from the viewpoint of others and not from their own 
perspectives (Zhang et al., 2020). Cultures with high collectivism suppress narcissistic personalities as well as the expression of narcissistic behaviors. This creates an environment that is much less friendly for narcissists to engage in CWB. It is much easier for narcissists to act in an individualistic culture than in a collectivist one (Zhang et al., 2020). A meta-analysis by Grijalva and Newman (2014) showed that the narcissism-CWB relationship was weaker in collectivist cultures. An interesting study by Meisel et al. (2016) compared Chinese and American students and found a higher level of narcissism in American culture. In Chinese culture, they found higher levels of overconfidence and risk-taking. They asserted that the higher levels of narcissism in American culture are a consequence of cultural influence. In China, overconfidence results from curricular practices in education, and risk-taking may result from dominant procedures developed through a dependence on social networks in times of loss. Based on the above explanation, it is possible that higher overconfidence and risk-taking may be a better correlate of CWB in Chinese culture.

This study did not show a direct relationship between the four situational variables examined and the CWB. This finding is similar to that reported by Liu and Cohen (2018), who examined physicians in China and suggests that personality is a strong correlate of CWB in Chinese culture. However, the findings here revealed five significant interactions that suggest that the environment affects the CWB of DTPs (Cohen, 2016). While the number of significant interactions was not high, some of them may have implications for future research and theory. First, the two interactions showed that transparency has a strong effect on Machiavellians' interpersonal and organizational CWB. Low transparency caused a very sharp slope at the level of the two forms of CWBs among higher levels of Machiavellians (Plot 1 in Figures 1 and 3). One explanation for the strong effect of transparency and Machiavellianism is that an organizational setting that is characterized by a lack of transparency toward job expectations and the expectations of superiors creates a friendlier and safer environment for Machiavellians to engage in CWB.

Another interesting interaction was psychopathy and organizational justice in interpersonal CWB (Plot 2 in Figure 2). The plot shows a sharp increase in the slope of the CWB for a high level of psychopathy when organizational justice was high. The opposite was expected in Hypothesis $4 \mathrm{~b}$. Support for the uniqueness of this finding can be found in Plot 3 in Figure 5, which shows that narcissists perform more organizational CWB when organizational justice is low, which is opposite to the one found for individuals with high psychopathic traits. A possible explanation for this finding is provided by Valentine et al. (2017), who argued that subclinical psychopaths, expressed in deviant behavior, impression management, and the manipulation of others, are more inclined to unethical reasoning in bullying situations, making them more likely to maintain bullying due to a deficiency in ethical sensitivity. This can happen regardless of the level of perceived organizational justice. Another explanation for this finding was provided by Brinke et al. (2015), who contended that psychopaths pay no attention to norms of fairness. Furthermore, psychopaths perceived others as highly vulnerable to manipulation and instrumental victimization (as hostages to be exploited) in pursuit of their goals. Therefore, norms of fairness and justice will not stop them in attaining their goals.

The current study has several limitations. First, the cross-sectional design makes it difficult to draw any causal conclusions. Second, the self-report measure of the CWB may have introduced a self-report bias. However, Berry et al. (2012) concluded, based on their comprehensive meta-analysis, that "ratings and self-ratings have mostly similar patterns and magnitudes of relationships with other variables, and other-ratings often do not account for appreciable incremental variance over self-ratings" (p. 625). Third, while the reliability of 0.60 for some of the study scales was considered acceptable (Dörnyei, 2003), it is a limitation, as higher reliabilities strengthen the validity of the findings.

Despite these limitations, the findings of this study are important and can contribute to a better understanding of CWB and DTP in healthcare and the nursing profession. However, additional studies on CWB and DTP in healthcare are required to confirm the findings of this study, particularly in more traditional collectivist cultures. In addition, there is a need to explore more moderators and mediators in the relationship between DTP and CWB, which will further enrich our understanding of the relationship between DTP and CWB. 


\section{References}

Adams, J. S. (1965). Inequity in Social Exchange. Advances in Experimental Social Psychology, 2, $267-299$. https://doi.org/10.1016/S0065-2601(08)60108-2

Ali, K., \& Johl, S. K. (2020). Impact of nurse supervisor on social exclusion and counterproductive behaviour of $\begin{array}{llllll}\text { employees. } \quad \text { Cogent } & \text { Business } & \text { \& } & \text { Management, } & 7(1), & \end{array}$ https://doi.org/10.1080/23311975.2020.1811044

Ammeter, A. P., Douglas, C., Ferris, G. R., \& Goka, H. (2004). A social relationship conceptualization of trust and accountability in organizations. Human Resource Management Review, 14(1), 47-65. https://doi.org/10.1016/j.hrmr.2004.02.003

Baka., Ł. (2018). When do the "dark personalities" become less counterproductive? The moderating role of job control and social support. International Journal of Occupational Safety and Ergonomics, 24(4), 557-569. https://doi.org/10.1080/10803548.2018.1463670

Baloch, M. A., Meng, F., Xu, Z., Cepeda-Carrion, I., \& Bari, M. W. (2017). Dark triad, perceptions of organizational politics and counterproductive work behaviors: The moderating effect of political skills. Frontiers in Psychology, 8, 1-14. https://doi.org/10.3389/fpsyg.2017.01972

Bennett, R. J., \& Robinson, S. L. (2000). Development of a measure of workplace deviance. Journal of Applied Psychology, 85(3), 349-360. https://doi.org/10.1037/0021-9010.85.3.349

Berry, C. M., Carpenter, N. C., \& Barratt, C. L. (2012). Do other-reports of counterproductive work behavior provide an incremental contribution over self-reports? A meta-analytic comparison. Journal of Applied Psychology, 97(3), 613-636. https://doi.org/10.1037/a0026739

Berry, C. M., Ones, D. S., \& Sackett, P. R. (2007). Interpersonal deviance, organizational deviance, and their common correlates: A review and meta-analysis. Journal of Applied Psychology, 92(2), 409-423. https://doi.org/10.1037/0021-9010.92.2.410

Boddy, C. R. (2010). Corporate psychopaths and organizational type. Journal of Public Affairs, 10(4), $300-312$. https://doi.org/10.1002/pa.365

Boddy, C. R. (2011). Corporate psychopaths: Organizational destroyers. London: Palgrave MacMillan. https://doi.org/10.1057/9780230307551

Boulter, L., \& Boddy, C. (2020). Subclinical psychopathy, interpersonal workplace exchanges and moral emotions through the lens of affective events theory (AET). Journal of Organizational Effectiveness: People and Performance, 8(1), 44-58. https://doi.org/10.1108/JOEPP-12-2019-0120

Bowling, N. A., \& Beehr, T. A. (2006). Workplace harassment from the victim's perspective: A theoretical model and meta-analysis. Journal of Applied Psychology, 91(5), 998-1012. https://doi.org/10.1037/0021-9010.91.5.998

Brooke, P. P., Russell, D. W., \& Price, J. L. (1988). Discriminant validation of measures of job satisfaction, job involvement and organizational commitment. Journal of Applied Psychology, 73, 139-145. https://doi.org/10.1037/0021-9010.73.2.139

Carpenter, N. C., Whitman, D. S., \& Amrhein, R. (2020). Unit-level counterproductive work behavior (CWB): A conceptual review and quantitative summary. Journal of Management, 47(6), 1498-1527. https://doi.org/10.1177/0149206320978812

Cicala, J. E., Bush, A. J., Sherrell, D. L., \& Deitz, G. D. (2014). Does transparency influence the ethical behavior of salespeople? Journal of Business Research, 67(9), 1787-1795. https://doi.org/10.1016/j.jbusres.2013.12.011

Cohen, A. (2015). Fairness in the workplace: A global perspective. New York: Palgrave McMillan. https://doi.org/10.1057/9781137524317

Cohen, A. (2016). Are they among us? A conceptual framework of the relationship between the dark triad personality and counterproductive work behaviors (CWBs). Human Resource Management Review, 26(1), 69-85. https://doi.org/10.1016/j.hrmr.2015.07.003

Cohen, A. (2018). Counterproductive work behaviors: Understanding the dark side of personalities in organizational life. New York: Routledge. https://doi.org/10.4324/9781315454818 
Cohen, A., \& Diamant, A. (2017). The role of justice perceptions in determining counterproductive work behaviors. The International Journal of Human Resource Management, 30(20), 1-24. https://doi.org/10.1080/09585192.2017.1340321

Cohen-Charash, Y., \& Mueller, J. S. (2007). Does perceived unfairness exacerbate or mitigate interpersonal counterproductive work behaviors related to envy? Journal of Applied Psychology, 92(3), 666. https://doi.org/10.1037/0021-9010.92.3.666

Dörnyei, Z. (2003). Attitudes, orientations, and motivations in language learning: Advances in theory, research, and applications. Language Learning, 53(S1), 3-32. https://doi.org/10.1111/1467-9922.53222

Ellis, S., Caridi, O., Lipshitz, R., \& Popper, M. (1999). Perceived error criticality and organizational learning: An empirical investigation. Knowledge and Process Management, 6(3), 166-175. https://doi.org/10.1002/(SICI)1099-1441(199909)6:3<166::AID-KPM65>3.0.CO;2-S

Furnham, A., \& Siegel, E. (2012). Reactions to organizational injustice: Counter work behaviors and the insider threat. In E. Kals \& J. Maes (Eds.), Justice and Conflicts (pp. 199-217). New York: Springer https://doi.org/10.1007/978-3-642-19035-3_12

Geng, Y., Chang, G., Li, L., Zhang, R., Sun, Q., \& Huang, J. (2016). Machiavellianism in Chinese adolescents: Links to internalizing and externalizing problems. Personality and Individual Differences, 89, 19-23. https://doi.org/10.1016/j.paid.2015.09.037

Geraghty, S. M. (2019). Examining perceived organizational injustice as a moderator in the relationship of dark tetrad personality traits to counterproductive work behavior. Master's thesis. Southern Illinois University, Carbondale, Illinois.

Ghislieri, C., Cortese, C. G., Molino, M., \& Gatti, P. (2019). The relationships of meaningful work and narcissistic leadership with nurses' job satisfaction. Journal of Nursing Management, 27(8), 1691-1699. https://doi.org/10.1111/jonm.12859

Griep, Y., Vantilborgh, T., \& Jones, S. K. (2018). The relationship between psychological contract breach and counterproductive work behavior in social enterprises: Do paid employees and volunteers differ? Economic and Industrial Democracy, 41(3), 727-745. https://doi.org/10.1177/0143831X17744029

Grijalva, E., \& Newman, D. A. (2015). Narcissism and counterproductive work behavior (CWB): Meta-analysis and consideration of collectivist culture, Big Five personality, and narcissism's facet structure. Applied Psychology, 64(1), 93-126. https://doi.org/10.1111/apps.12025

Grimmelikhuijsen, S. G., \& Welch, E. W. (2012). Developing and testing a theoretical framework for computer-mediated transparency of local governments. Public Administration Review, 72(4), 562-571. https://doi.org/10.1111/j.1540-6210.2011.02532.x

Harman, H. (1967). Modern factor analysis. Chicago: University of Chicago Press.

Hayes, A. F. (2013). Introduction to mediation, moderation, and conditional process analysis: A regression-based approach. New York, NY: Guilford Press.

Hochwarter, W. A., Perrewé, P. L., Hall, A. T., \& Ferris, G. R. (2005). Negative affectivity as a moderator of the form and magnitude of the relationship between felt accountability and job tension. Journal of Organizational Behavior, 26(5), 517-534. https://doi.org/10.1002/job.324

Jensen, J. M., Opland, R. A., \& Ryan, A. M. (2010). Psychological contracts and counterproductive work behaviors: Employee responses to transactional and relational breach. Journal of Business and Psychology, 25(4), 555-568. https://doi.org/10.1007/s10869-009-9148-7

Johns, G. (1999). A multi-level theory of self-serving behavior in and by organizations. In R. I. Sutton, \& B. M. Staw (Eds.), Research in Organizational Behavior (pp. 1-38). New York: Elsevier Science/JAI Press.

Jonason, P. K., \& Webster, G. D. (2010). The dirty dozen: A concise measure of the dark triad. Psychological Assessment, 22(2), 420-432. https://doi.org/10.1037/a0019265

Labrague, L. J., Lorica, J., Nwafor, C. E., \& Cummings, G. G. (2020). Predictors of toxic leadership behaviour among nurse managers: A cross-sectional study. Journal of Nursing Management, 29(2), 165-176. https://doi.org/10.1111/jonm.13130 
Li, S., \& Chen, Y. (2018). The relationship between psychological contract breach and employees' counterproductive work behaviors: the mediating effect of organizational cynicism and work alienation. Frontiers in Psychology, 9, 1273. https://doi.org/10.3389/fpsyg.2018.01273

Li, S., Ding, D., Wu, Z., Yi, L., Lai, J., \& Dang, L. (2020, December). Do high psychopaths care more about moral consequences than low psychopaths in Chinese culture? An exploration using the CNI model. Healthcare, 8(4), 505. Multidisciplinary Digital Publishing Institute. https://doi.org/10.3390/healthcare8040505

Luo, Y. (2005). An organizational perspective of corruption. Management and Organization Review, 1(1), 119-154. https://doi.org/10.1111/j.1740-8784.2004.00006.x

Mahmood, Z., Alonazi, W. B., Baloch, M. A., \& Lodhi, R. N. (2021). The dark triad and counterproductive work behaviours: A multiple mediation analysis. Economic Research-Ekonomska Istraživanja, 1-22. https://doi.org/10.1080/1331677X.2021.1874463

Martin, L. E., Brock, M. E., Buckley, M. R., \& Ketchen, D. J. (2010). Time banditry: Examining the purloining of time in organizations. Human Resource Management Review, 20(1), 26-34. https://doi.org/10.1016/j.hrmr.2009.03.013

Mathieu, J. E., \& Farr, J. L. (1991). Further evidence of the discriminant validity of measures of organizational commitment, job involvement, and job satisfaction. Journal of Applied Psychology, 76, 127-133. https://doi.org/10.1037/0021-9010.76.1.127

Meisel, M. K., Ning, H., Campbell, W. K., \& Goodie, A. S. (2016). Narcissism, overconfidence, and risk taking in US and Chinese student samples. Journal of Cross-Cultural Psychology, 47(3), 385-400. https://doi.org/10.1177/0022022115621968

Niehoff, B. P., \& Moorman, R. H. (1993). Justice as a mediator of the relationship between methods of monitoring and organizational citizenship behavior. Academy of Management Journal, 36(3), 527-556. https://doi.org/10.5465/256591

Nigro, T. L. (2018). The shadows in healthcare leadership. Healthcare Management Forum, 31(3), 97-102. https://doi.org/10.1177/0840470417745082

Nuzulia, S., \& Why, F. Y. P. (2020). When the dark shines: The role of dark personality traits in leadership role occupancy and hiring decisions in a collectivistic culture. Social Psychological and Personality Science, 11(8), 1089-1100. https://doi.org/10.1177/1948550619893956

O'Boyle Jr., E. H., Forsyth, D. R., Banks, G. C., \& McDaniel, M. A. (2012). A meta-analysis of the dark triad and work behavior: A social exchange perspective. Journal of Applied Psychology, 97(3), 557-579. https://doi.org/10.1037/a0025679

Palmer, J. C., Komarraju, M., Carter, M. Z., \& Karau, S. J. (2017). Angel on one shoulder: Can perceived organizational support moderate the relationship between the dark triad traits and counterproductive work behavior? Personality and Individual Differences, 110, 31-37. https://doi.org/10.1016/j.paid.2017.01.018

Pan, W., Zhang, Q., Teo, T. S., \& Lim, V. K. (2018). The dark triad and knowledge hiding. International Journal of Information Management, 42, 36-48. https://doi.org/10.1016/j.ijinfomgt.2018.05.008

Podsakoff, P. M., \& Organ, D. (1986). Self-reports in organizational research: Problems and prospects. Journal of Management, 12, 531-544. https://doi.org/10.1177/014920638601200408

Robertson, S. A., Datu, J. A. D., Brawley, A. M., Pury, C. L., \& Mateo, N. J. (2016). The dark triad and social behavior: The influence of self-construal and power distance. Personality and Individual Differences, 98, 69-74. https://doi.org/10.1016/j.paid.2016.03.090

Robinson, S. L., \& Morrison, E. (2000). The development of psychological contract breach and violation: A longitudinal study. Journal of Organizational Behavior, 21, 525-546. https://doi.org/10.1002/1099-1379(200008)21:5<525::AID-JOB40>3.0.CO;2-T

Schilbach, M., Baethge, A., \& Rigotti, T. (2020). Why employee psychopathy leads to counterproductive workplace behaviours: an analysis of the underlying mechanisms. European Journal of Work and Organizational Psychology, 29(5), 693-706. https://doi.org/10.1080/1359432X.2020.1739650

Schilpzand, P., De Pater, I. E., \& Erez, A. (2016). Workplace incivility: A review of the literature and agenda for future research. Journal of Organizational Behavior, 37(1), S57-S88. https://doi.org/10.1002/job.1976 
Schyns, B., \& Schilling, J. (2013). How bad are the effects of bad leaders? A meta-analysis of destructive leadership and its outcomes. The Leadership Quarterly, 24(1), 138-158. https://doi.org/10.1016/j.leaqua.2012.09.001

Smith, S. F., \& Lilienfeld, S. O. (2013). Psychopathy in the workplace: The knowns and unknowns. Aggression and Violent Behavior, 18, 204-218. https://doi.org/10.1016/j.avb.2012.11.007

Stout, M. (2005a). The ice people: Living among us are people with no conscience, no emotions and no conception of love: Welcome to the chilling world of the sociopath. Psychology Today, 38(1), 72-76.

Stout, M. (2005b). The sociopath next door: The ruthless vs. the rest of us. New York: Broadway Books.

Thibault, T., \& Kelloway, E. K. (2020). Personality and counterproductive work behavior. The Wiley encyclopedia of personality and individual differences: Clinical, applied, and cross-cultural research, 599-603. https://doi.org/10.1002/9781118970843.ch364

Valentine, S. R., Hanson, S. K., \& Fleischman, G. M. (2017). The spiraling and spillover of misconduct: perceived workplace bullying, subclinical psychopathy, and businesspersons' recognition of an ethical issue. Employee Responsibilities and Rights Journal, 29, 221-244. https://doi.org/10.1007/s10672-017-9302-8

Yang, J., \& Diefendorff, J. M. (2009). The relations of daily counterproductive workplace behavior with emotions, situational antecedents, and personality moderators: A diary study in Hong Kong. Personnel Psychology, 62(2), 259-295. https://doi.org/10.1111/j.1744-6570.2009.01138.x

Yao Jr, J. J. (2019). Nurses gone bad: Predictors of counterproductive behavior of nurses. Asian Journal of Science and Technology, 10(9), 10259-10265.

Ying, L., \& Cohen, A. (2018). Dark triad personalities and counterproductive work behaviors among physicians in China. The International Journal of Health Planning and Management, 33(4), e985-e998. https://doi.org/10.1002/hpm.2577

Youli, H., \& Chao, L. (2015). A comparative study between the Dark Triad of personality and the Big Five. Canadian Social Science, 11(1), 93-98. https://doi.org/10.3968/5715

Zagenczyk, T. J., Smallfield, J., Scott, K. L., Galloway, B., \& Purvis, R. L. (2017). The moderating effect of psychological contract violation on the relationship between narcissism and outcomes: An application of trait activation theory. Frontiers in Psychology, 8, 1113. https://doi.org/10.3389/fpsyg.2017.01113

Zaghini, F., Fida, R., Caruso, R., Kangasniemi, M., Sili, A., \& Vergata, P. (2016). What is behind counterproductive work behaviors in the nursing profession? A systematic review. Journal of Clinical Research and Bioethics, 7(4), 1-7. https://doi.org/10.4172/2155-9627.1000277

Zhang, J., Ziegler, M., \& Paulhus, D. L. (2020). Development and evaluation of the short Dark Triad Chinese version (SD3-C). Current Psychology, 39, 1161-1171. https://doi.org/10.1007/s12144-019-00272-3

Zhao, H., Zhang, H., \& Xu, Y. (2016). Does the Dark Triad of personality predict corrupt intention? The mediating role of belief in good luck. Frontiers in Psychology, 7, 608. https://doi.org/10.3389/fpsyg.2016.00608

Zheng, W., Wu, Y. C. J., Chen, X., \& Lin, S. J. (2017). Why do employees have counterproductive work behavior? The role of founder's Machiavellianism and the corporate culture in China. Management Decision, 55(3), 563-578. https://doi.org/10.1108/MD-10-2016-0696

\section{Copyrights}

Copyright for this article is retained by the author(s), with first publication rights granted to the journal.

This is an open-access article distributed under the terms and conditions of the Creative Commons Attribution license (http://creativecommons.org/licenses/by/4.0/). 